\title{
Morphological adrenarche in rhesus macaques: development of the zona reticularis is concurrent with fetal zone regression in the early neonatal period
}

\author{
Ann D Nguyen, Samantha M Mapes, C Jo Corbin and Alan J Conley \\ Department of Population Health and Reproduction, School of Veterinary Medicine, University of California, Davis, California 95616, USA \\ (Correspondence should be addressed to A J Conley; Email: ajconley@ucdavis.edu)
}

\begin{abstract}
Human adrenarche is associated with the establishment of a functional zona reticularis (ZR) and increasing secretion of dehydroepiandrosterone (DHEA) in sulfated form (DS). Like most non-human primates, rhesus macaques are not believed to undergo adrenarche, though they clearly establish a functional ZR after birth. However, the origins of the rhesus $Z R$ are not well defined. Therefore, we investigated the zonal development, steroidogenic enzyme expression and morphology of rhesus adrenals from 1 day to 14 months of age. Immunohistochemistry was conducted to determine expression profiles of the steroidogenic enzymes $17 \alpha-$ hydroxylase/17,20-lyase cytochrome P450, family 17, subfamily A, polypeptide 1 (CYP17A1), cytochrome P450, family 21 , subfamily A, polypeptide 2 (CYP21A2), hydroxy$\Delta$-5-steroid dehydrogenase, $3 \beta$ - and steroid $\Delta$-isomerase 2 (HSD3B2), the redox partner NADPH-cytochrome P450 oxidoreductase (CPR), as well as the accessory protein cytochrome b5 (b5), a marker of the primate ZR. The rhesus
\end{abstract}

$\mathrm{ZR}$ is mature by 3 months of age based on differentiation of the innermost zone that lacks HSD3B2, but exhibits increased b5 expression during this period. Further, the $\mathrm{ZR}$ develops in neonates from a previously described dense band of cells which we show expresses b5, CYP17A1, CPR, and CYP21A2 throughout maturation. The fetal zone (FZ) is distinguished from the ZR by its lack of CYP21A2, and ZR development proceeded as the FZ regressed with two important implications: neither FZ regression nor ZR maturation can be monitored independently by circulating adrenal androgens, and these events must be induced by different factors in rhesus, and likely humans. Collectively these data demonstrate that ZR development begins before birth in the rhesus, proceeding concomitantly with FZ regression post-natally, suggesting that rhesus experiences morphological adrenarche during the first three months of life.

Journal of Endocrinology (2008) 199, 367-378

\section{Introduction}

Among mammals, the human adrenal gland is unusual in that it develops the capacity to secrete prodigious amounts of the C-19 steroid dehydroepiandrosterone (DHEA) and its sulfoconjugate (DS) during childhood, an event commonly referred to as adrenarche. Adrenarche is associated with differentiation of an inner zone of cells in the adrenal cortex, the zona reticularis (ZR; Havelock et al. 2004). Although many non-human primates also develop a prominent $Z R$, adrenarche is not thought to occur in the most commonly studied species such as the rhesus macaque (Arlt et al. 2002). This perception derives from the lack of data demonstrating a postnatal increase in circulating DHEA or DS in juvenile and adolescent animals (Cutler et al. 1978, Smail et al. 1982). However, immunohistochemical (IHC) studies confirm that the rhesus $\mathrm{ZR}$ has the functional capacity for androgen synthesis (Mapes et al. 1999), similar to the human ZR (Conley et al. 2004). As in humans, rhesus adrenal development is also associated with regression of an equally distinct fetal zone (FZ) during the neonatal period (McNulty et al. 1981). Given the parallels in fetal and adult adrenocortical differentiation in both species, it seems that the rhesus macaque must experience an adrenarche. Thus, a more careful definition of neonatal adrenocortical differentiation may shed light on why adrenarche in the rhesus is not marked by a pre-pubertal increase in DS, and is therefore hormonally cryptic.

Clearly, adrenocortical development and differentiation is quite complex in human and non-human primates (Winter 1992), involving changes in patterns of steroidogenic enzyme expression that dictate the profile of steroids produced by each zone (Mesiano et al. 1993, Conley \& Bird 1997, Jaffe et al. 1998). The mature primate adrenal cortex synthesizes and secretes aldosterone, cortisol, and DS from the zona glomerulosa $(\mathrm{ZG})$, zona fasciculata $(\mathrm{ZF})$ and the $\mathrm{ZR}$ respectively. It has been suggested that the adult $Z R, Z F$, and $Z G$ develop from histologically distinct zones of the fetal 
adrenal cortex, namely the FZ, transitional zone (TZ) and definitive zone (DZ) respectively, based on results of IHC studies (Mesiano et al. 1993). The FZ secretes androgens, primarily DS, though little cortisol or aldosterone is synthesized from the TZ and DZ during fetal life (Seron-Ferre et al. 1978, Doody et al. 1990, Nelson et al. 1990). As expected, the ZR and FZ express the steroidogenic enzymes, and accessory proteins, required for androgen synthesis, including $17 \alpha$-hydroxylase/17,20-lyase cytochrome P450, family 17 , subfamily A, polypeptide 1 (CYP17A1), cytochrome b5 (b5), and NADPH-cytochrome P450 oxidoreductase (CPR; Mesiano et al. 1993, Coulter et al. 1996b, Mapes et al. 1999, 2002, Suzuki et al. 2000, Narasaka et al. 2001, Dharia et al. 2004, 2005). The adult ZF and ZG, and to a limited extent the fetal TZ and DZ as noted above, exhibit expression profiles of steroidogenic enzymes that support glucocorticoid and mineralocorticoid syntheses instead (Mesiano et al. 1993, Coulter et al. 1996b, Coulter \& Jaffe 1998, Mapes et al. 1999, Suzuki et al. 2000, Narasaka et al. 2001). These enzymes include cytochrome P450, family 21, subfamily A, polypeptide 2 (CYP21A2), hydroxy- $\Delta$-5-steroid dehydrogenase, $3 \beta$ - and steroid $\Delta$-isomerase 1 (HSD3B2) and 11 $\beta$-hydroxylase cytochrome P450 (P450c11). Thus, the temporal and spatial expression profiles of key steroidogenic enzymes, redox partners and accessory proteins, together with routine histology, allows the zones of the adult and fetal adrenal to be identified, characterized, and distinguished.

The current study was conducted to investigate the temporal and spatial profiles of expression of a suite of steroidogenic enzymes and accessory proteins, especially those necessary for androgen synthesis in neonatal rhesus adrenal glands. The immediate post partum and early neonatal period is a particularly dynamic one where differentiation of the adrenal cortex of rhesus macaques is concerned (McNulty et al. 1981), but it has not been extensively investigated in this species with respect to functional differentiation. Therefore, it was anticipated that better defining the cellular differentiation and zonation of the rhesus adrenal cortex during the early neonatal period would provide insight into ZR development, the event associated with adrenarche, in humans and nonhuman primates.

\section{Materials and Methods}

\section{Animals}

Rhesus macaque adrenals were obtained opportunistically from approved projects at the California National Primate Research Center. Specimens were obtained from animals that were perinatal (1-14 days old; $n=10)$ neonatal (1-3 months old; $n=12$ ), juvenile (4-14 months old; $n=11$ ) or adult ( 8 years or older; $n=4)$ in age. Adrenal glands were fixed in $4 \%$ paraformaldehyde and subjected to graded ethanol baths prior to embedding. Tissues were embedded in paraffin wax (Fisher Scientific, Pittsburgh, PA, USA) and sectioned at $5 \mu \mathrm{m}$ thickness.

\section{Immunohistochemistry}

Tissue sections were deparaffinized with Citrisolv and rehydrated through a graded ethanol series. Localization of expression of steroidogenic enzymes was visualized by avidinbiotin-peroxidase complex formation (Vectastain Elite ABC kit, Vector Laboratories, Burlingame, CA, USA), as previously described (Conley et al. 1996, Browne et al. 2006). Additional adrenal tissue sections were also subjected to routine hematoxylin and eosin staining (Fig. 1). Steroidogenic enzyme expression was detected in sections from each subject using the following primary antisera: b5 ((1:20 000), polyclonal rabbit anti-human, raised in our laboratory against purified recombinant protein provided by Drs Ron Estabrook and Manju Shet (Department of Biochemistry, University of Texas Southwestern Medical Center, Dallas, TX, USA)), CYP17A1 $((1: 10000)$, polyclonal chicken anti-human raised in our laboratory against purified recombinant protein), CPR ((1:3000), polyclonal rabbit anti-rat raised in our laboratory against purified recombinant protein provided by Dr Ron Estabrook), CYP21A2 ((1:25 000), polyclonal rabbit antihuman provided by Dr Walter Miller (Department of Pediatrics, University of California San Francisco, San Francisco, CA, USA)), and HSD3B2 ((1:400), polyclonal rabbit anti-human provided by Dr J Ian Mason (Centre for Reproductive Biology, University of Edinburgh Medical School, Edinburgh, UK)). PBS $(0 \cdot 1 \mathrm{M}, \mathrm{pH} 7 \cdot 2$ with $0.3 \%$ Triton-X (Sigma-Aldrich)) was used for tissue washes and antibody dilutions. Endogenous peroxidase activity was quenched by incubation in $0.3 \% \mathrm{H}_{2} \mathrm{O}_{2}$ (in methanol, room temperature (RT)) for $30 \mathrm{~min}$. Immunolocalization with CYP21A2 and CPR antisera utilized antigen retrieval, performed as previously described (Browne et al. 2006), prior to blocking of non-specific binding. Briefly, sections immersed in Antigen Unmasking Solution (Vector Laboratories) were heated slowly to $95^{\circ} \mathrm{C}$ in a steamer, cooled gradually to RT over $45 \mathrm{~min}$, and then subjected to the remainder of the IHC procedure. Non-specific binding was blocked by incubation with $1.5 \%$ normal goat serum in PBS (20 min, RT). Tissue sections were incubated with primary antibody incubation overnight at $4{ }^{\circ} \mathrm{C}$ for all antisera, followed by $30 \mathrm{~min}$ incubations with species-appropriate biotinylated secondary antibody (chicken: Santa Cruz Biotechnology Inc., Santa Cruz, CA, USA; rabbit: Vectastain Elite ABC kit, Vector Laboratories) and avidin-biotin complex solution (Vectastain Elite ABC kit, Vector Laboratories). Primary antibody binding was detected with the peroxidase substrates Vector NovaRed (b5, CYP17A1; 5 min incubation) or 3-amino-9-ethylcarbazole (AEC: CYP21A2, HSD3B2, CPR; 12 min incubation; Vector Laboratories) and counterstained with Gill's hematoxylin 2 (Fisher Scientific). Tissues stained with Vector NovaRed were dehydrated with graded EtOH series and Citrisolv baths. Vector NovaRed-stained slides were coverslipped using Permount mounting medium (Fisher Scientific); slides stained with AEC were coverslipped using Faramount aqueous mounting medium (Dako, Carpinteria, CA, USA). Specificity 


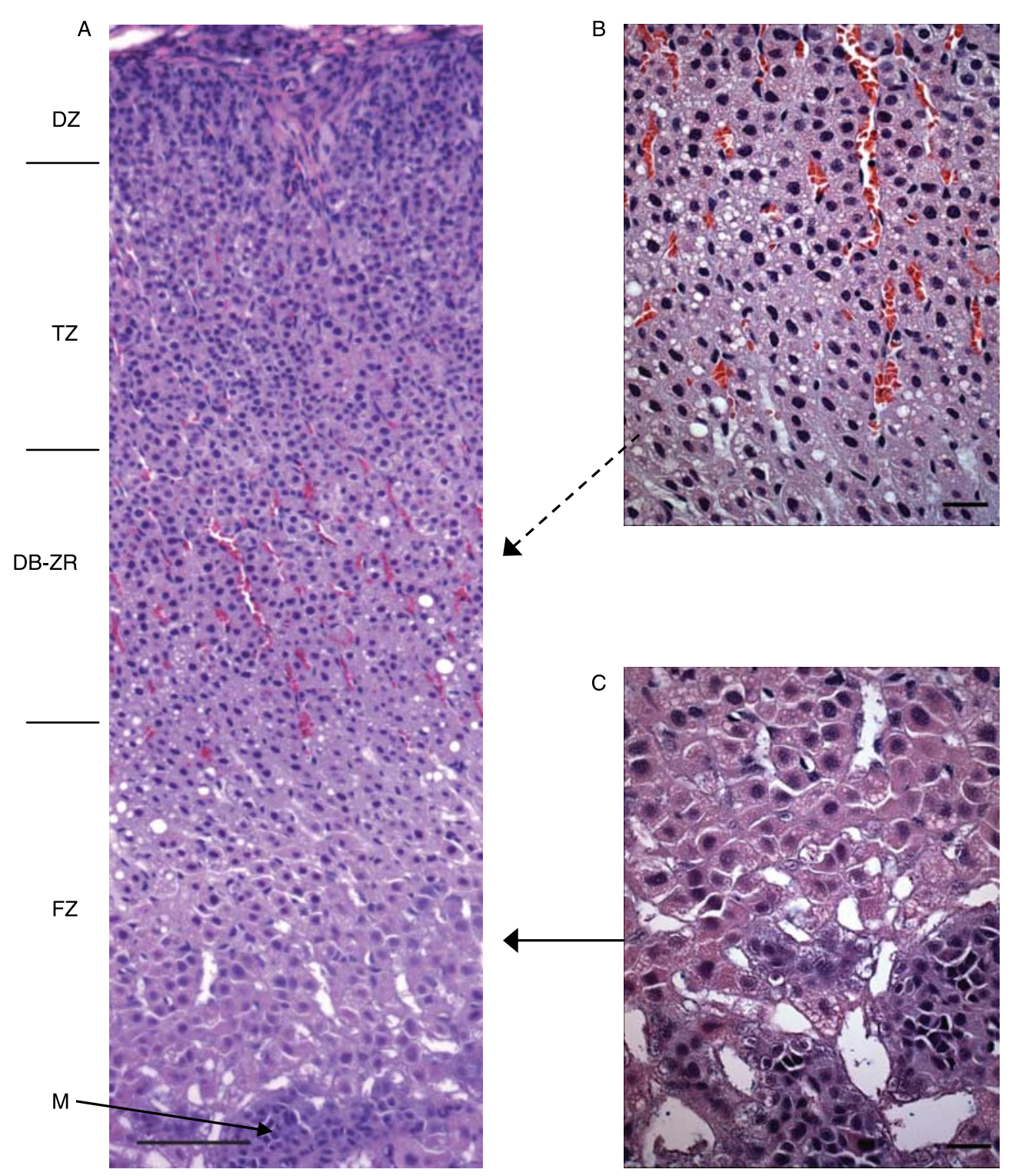

Figure 1 Cortical zonation of the perinatal rhesus adrenal gland, routine H\&E. A Four morphologically distinct regions are evident in the adrenal cortex at 5 days of age: the fetal zone (FZ), transitional zone (TZ), definitive zone (DZ), and the dense band (DB-ZR) of cells with reduced cytoplasmic volume separating the TZ and FZ. FZ cells are large and vacuolated (solid arrow, C close-up) and lie adjacent to the medulla (M). Cells of the DB-ZR are closely packed, with sparse cytoplasm, and are situated between the TZ and FZ (dashed arrow, B close-up). A, bar $=100 \mu \mathrm{m} ; \mathrm{B}$ and C, bars $=25 \mu \mathrm{m}$.

of all antisera binding was verified by western immunoblotting of rhesus macaque adrenal microsomal samples, all of which demonstrated single bands of the expected molecular size (Figs 2-4). Normal serum was utilized instead of primary antisera in negative controls. Micrographs were taken using brightfield illumination on a DMRB microscope (Leica Corp., Rockleigh, NJ, USA) equipped with a MicroPublisher 3.3 RTV (Qimaging Corporation, Surrey, British Columbia, Canada) and Windows QCapture Suite (Qimaging Corporation). IHC runs for each enzyme included specimens from all ages to minimize variation in staining that might have occurred between different runs.

\section{Results}

\section{Perinatal zonation}

The perinatal (1-14 days old) rhesus adrenal cortex (Fig. 1) was comprised of four distinct regions. Directly underlying the capsule was the DZ, consisting of a band of small cells, 
1 DO

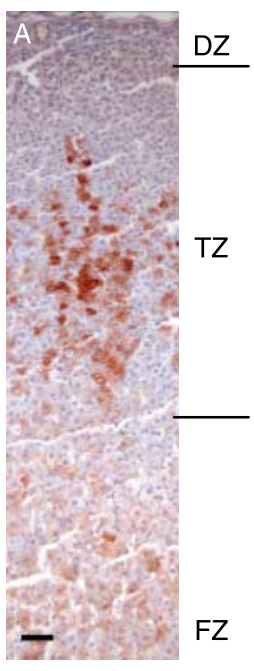

FZ
$3 \mathrm{DO}$

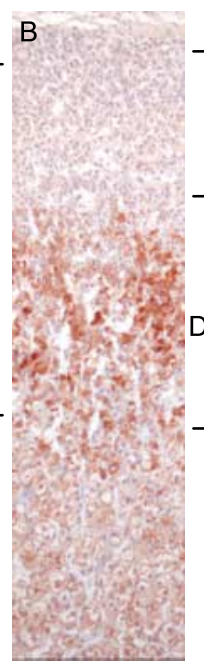

14 DO

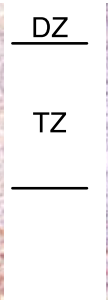

B-ZR

FZ

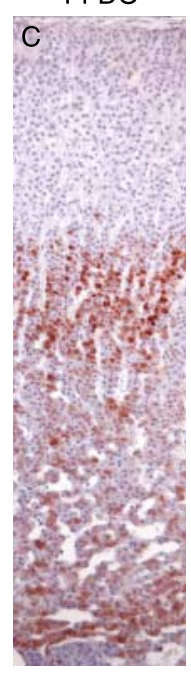

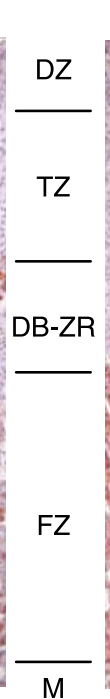

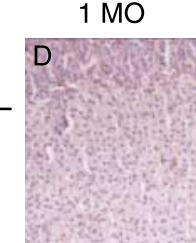

ZG

ZF

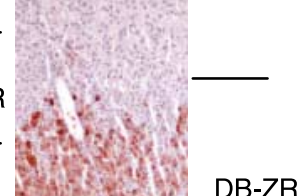

FZ
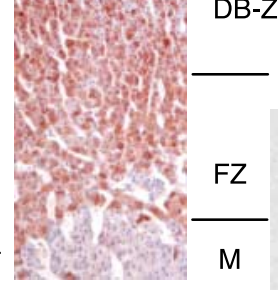

. $50 \mathrm{kDa}$

$1.3 \mathrm{YO}$
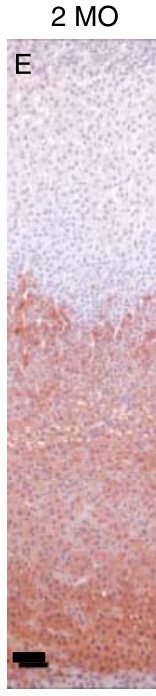

$3 \mathrm{MO}$

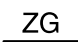

ZF
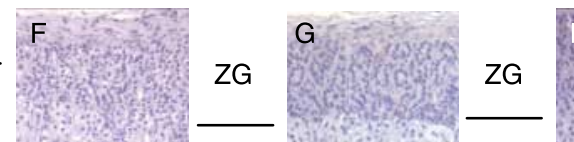

8 YO

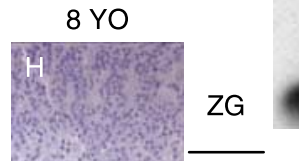

$.15 \mathrm{kDa}$

Figure 2 Cytochrome b5 expression in the developing rhesus adrenal cortex ( 1 day old (DO)-1 month old ( $\mathrm{MO}$; $\mathrm{A}-\mathrm{D})$ and $2 \mathrm{MO}-8$ years of age $(\mathrm{YO} ; \mathrm{E}-\mathrm{H})$ ). ( $\mathrm{A}$ and $\mathrm{B}$ ) Perinatal period ( 1 and $3 \mathrm{DO}$ respectively); there is patchy expression throughout the fetal zone (FZ) and the transitional zone (TZ) adjacent to it, but expression is more intense in the positive cells of the TZ. The dense band (DB-ZR) is evident between the TZ and FZ in the 3 DO tissue, consisting of compact cells with intense b5-expression, much greater than cells of either the FZ or the TZ. The outermost definitive (DZ) has no detectable b5 expression by comparison. (C) Perinatal period (14 DO); there is increased intensity of b5 expression in the $F Z$, although expression in the DB-ZR is still greater. The DZ and medulla $(\mathrm{M})$ are negative for b5 expression. A small number of TZ cells near the DB-ZR show b5 expression. (D) Neonatal period ( $1 \mathrm{MO}$ ); nearly all DB-ZR and FZ cells are positive for b5 expression in the region between a distinct b5-negative zona fasciculata (ZF) and $M$. The FZ, while still b5-positive, is decreasing in size, and there is no detectable b5 expression in the zona glomerulosa (ZG). (E) Neonatal period (2 MO); all DB-ZR and FZ cells are positive for b5 expression in the region between a distinct b5-negative ZF and M. Compact cells of the DB-ZR exhibit increased intensity of expression, similar to perinatal adrenals. The FZ, while still b5-positive, continues to shrink in size. There is no detectable b5 expression in the ZG or M. (F) Neonatal period (3 MO); there is uniform b5 expression throughout the zona reticularis (ZR), as seen in adrenal cortex of mature rhesus. Between the b5-positive compact cells of the ZR and the b5-negative cells of the $M$ is a thin layer of large, vacuolated b5positive cells of the diminished FZ. (G) Juvenile (1.3 YO); expression of b5 is similar to that observed in the ZR of neonates $3 \mathrm{MO}$ and older. $(\mathrm{H})$ Adult $(8 \mathrm{YO})$; note expression is uniform in intensity in all cells, similar to that seen in the $3 \mathrm{MO}$ ZR. In adults, no cells exhibiting FZ morphology were detected within the b5-positive region between the b5-deficient ZF and M. Bars $=50 \mu \mathrm{m}$, all panels same magnification. 


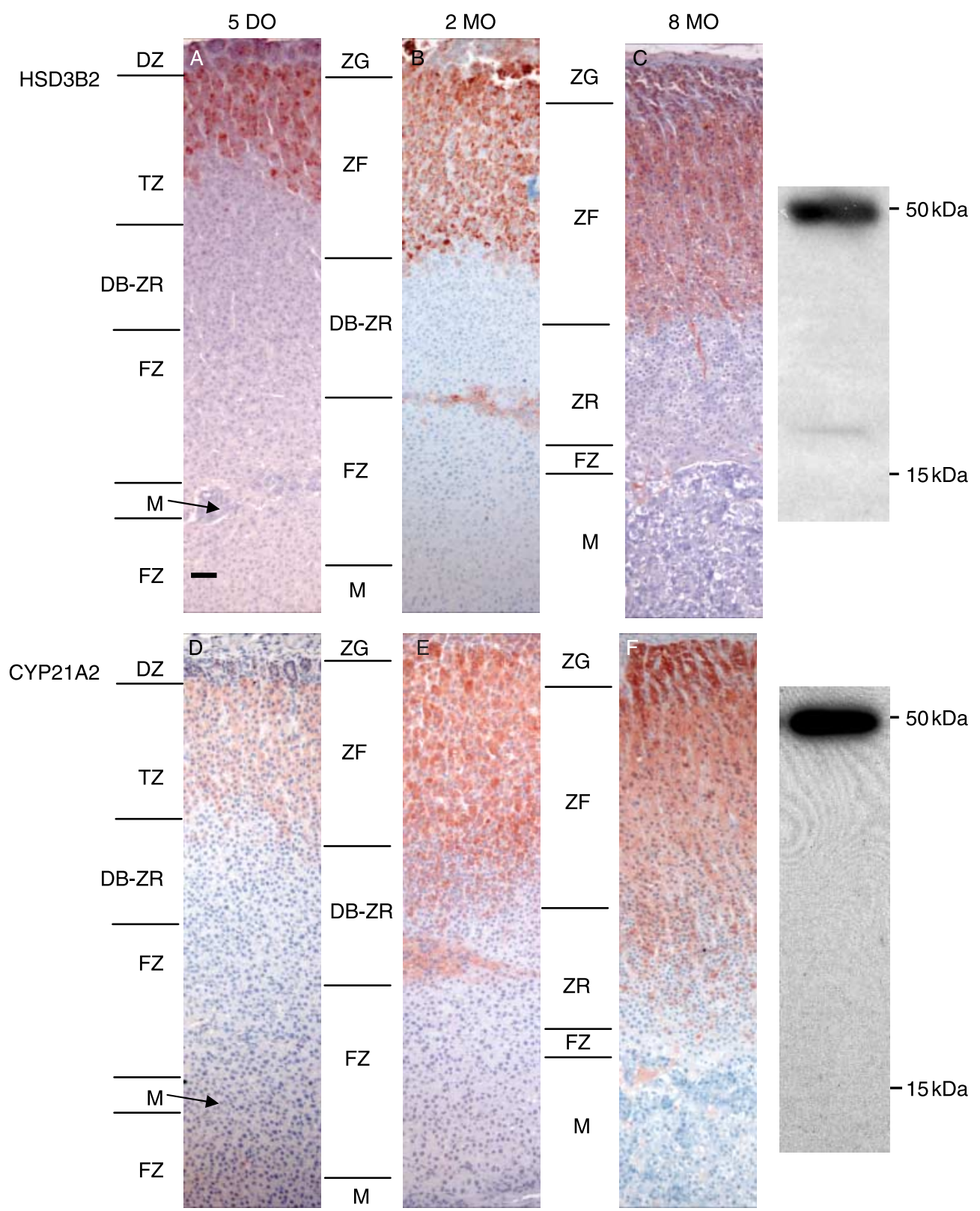

Figure 3 Adrenocortical expression of HSD3B2 (A-C) and CYP21A2 (D-F) in the developing rhesus from 5 days (DO)-8 months old (MO). (A) Perinatal (5 DO); expression of HSD3B2 is restricted to the outer definitive zone (DZ) and the outermost region of the transitional zone (TZ). (B) Neonatal (2 MO); HSD3B2 is expressed in all cells of the zona glomerulosa (ZG) and zona fasciculata (ZF), with greatest expression in the ZG. Non-specific staining due to a fold in adrenal tissue is seen at the dense band (DB-ZR)/fetal zone (FZ) border. No HSD3B2 expression was detected in the DB-ZR, FZ, or medulla (M). (C) Juvenile (8 MO); HSD3B2 is expressed in all cells of the ZG and ZF, but is the greatest in the ZG and outermost ZF. No HSD3B2 expression was detected in ZR, FZ, or M cells. (D) Perinatal (5 DO); CYP21A2 is expressed in the DZ, TZ, and faintly in some cells of the DB-ZR. A few FZ cells show faint CYP21A2 staining. (E) Neonatal (2 MO); CYP21A2 expression was intense throughout the ZG, ZF, and outermost DB-ZR, with no detectable expression in the $\mathrm{FZ}$ (based on morphological assessment) or $\mathrm{M}$. (F) Juvenile $(8 \mathrm{MO})$; there is strong expression of CYP21A2 in all cells of the ZG and ZF, and strong but patchy expression in cells of the ZR. There was no detectable expression in the vacuolated cells of the FZ or in M. Arrows denote clusters of medullary cells. Bar $=50 \mu \mathrm{m}$, all panels same magnification. 


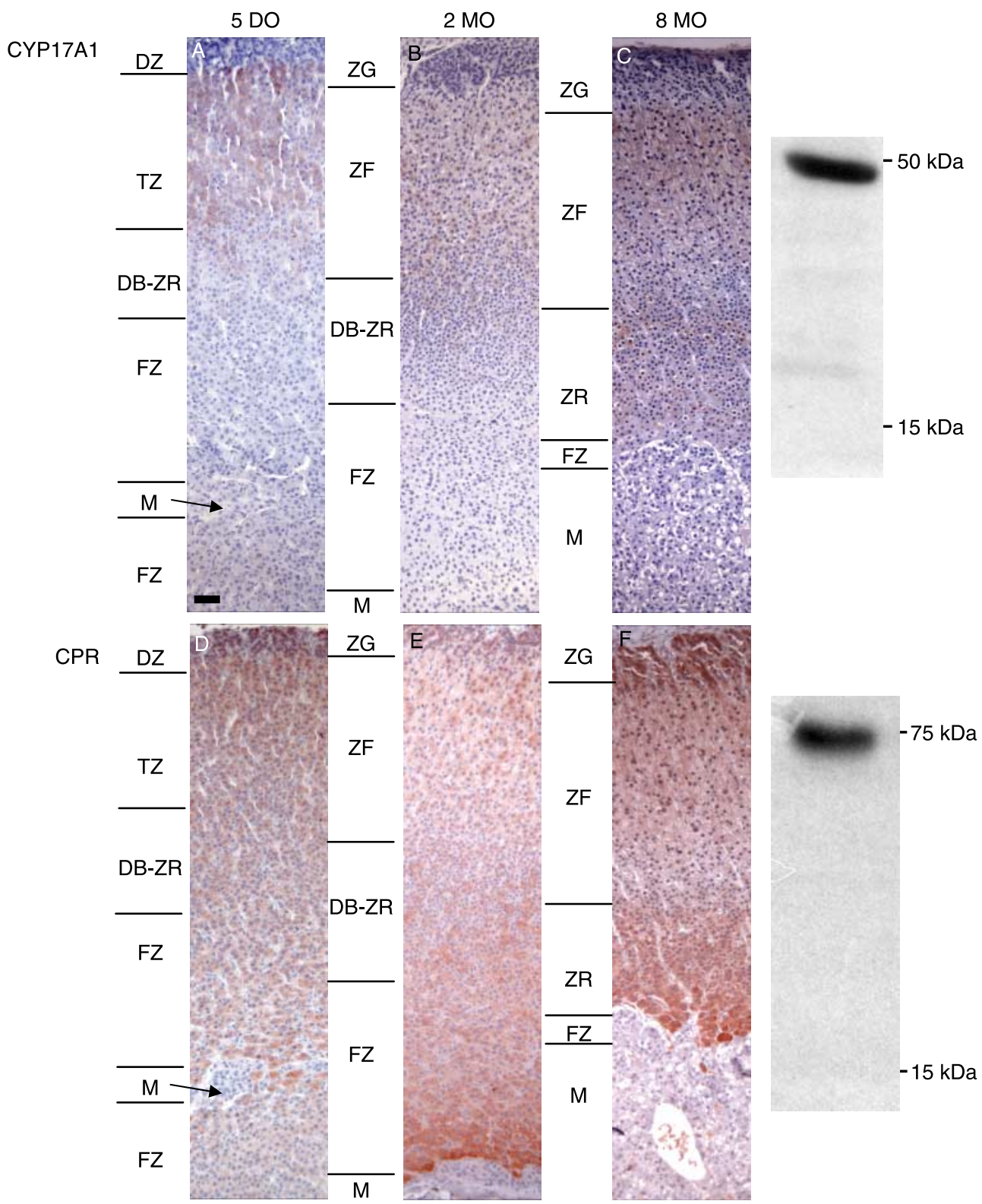

Figure 4 Developmental expression of $17 \alpha$-hydroxylase/17,20-lyase cytochrome P450 (CYP17A1; A-C) and $\mathrm{NADPH}$-cytochrome P450 oxidoreductase (CPR; D-F) in the developing rhesus adrenal (5 day old (DO)-8 months old (MO)). (A) Perinatal (5 DO); there is faint expression of CYP17A1 in some large, vacuolated cells of the fetal zone (FZ) and intense expression in all transitional zone (TZ) cells. Cells of the dense band (DB-ZR) between the $T Z$ and $F Z$ exhibit intermediate expression relative to these zones. No detectable expression in the definitive zone (DZ) was observed. (B) Neonatal (2 MO); all cells of the ZF and the outermost cells of the DB-ZR exhibit uniform expression of CYP17A1. FZ cells exhibit faint, if any, CYP17A1 expression. There is no detectable expression of CYP17A1 in the zona glomerulosa (ZG) or medulla (M). (C) Juvenile (8 MO); CYP17A1 was expressed throughout the ZF and zona reticularis (ZR). The cells at the ZG/ZF border exhibit strong, uniform P45017 expression, patchy expression is seen throughout the innermost ZF and the ZR. There is very faint, if any, expression of CYP17A1 in the diminished FZ and no detectable expression of in the ZG or M. (D and E) Perinatal/Neonatal (1DO/2 MO); CPR was detected throughout the adrenal cortex, with no detectable expression in the M. (F) Juvenile (8 MO); CPR is detected throughout the adrenal cortex with cells of the $\mathrm{FZ}$ at the corticomedullary junction and the ZG exhibiting the greatest intensity of CPR expression. There is no detectable expression in the M. Arrows denote clusters of medullary cells. Bar $=50 \mu \mathrm{m}$, all panels are the same magnification. 
densely packed in columnar arrangements. Immediately adjacent to the $\mathrm{DZ}$ were the cells of the $\mathrm{TZ}$, defined by their larger diameter, compact nuclei and lack of columnar organization (Fig. 1A). The innermost region of the perinatal adrenal cortex was comprised of the large, spongy cells of the FZ that were generally disorganized like the TZ cells (Fig. 1A and C). Separating the TZ and the FZ, and completely distinct from the surrounding regions, was a band of tightly packed cells with little cytoplasm, hereafter referred to as the dense band (DB-ZR; Fig. 1A and B). All perinatal specimens examined exhibited a distinct DB-ZR as illustrated in Fig. 1.

\section{Localization of 65}

In the perinatal adrenals, $b 5$ immunostaining was detected in the TZ and throughout the FZ. Expression of b5 was patchy in both inner zones, with immunostaining more intense in the compact cells of the $\mathrm{TZ}$ than the large vacuolated $\mathrm{FZ}$ cells (Fig. 2A). The DB-ZR at the boundary between the FZ and $\mathrm{TZ}$ also stained strongly for b5 expression during this early perinatal period (Fig. 2B). The proportion of b5-positive cells and the intensity of expression in the TZ, FZ, and DB-ZR increased throughout these first 4 weeks of life (Fig. 2A-C). By 1 month of age (defined as the onset of the neonatal period), the cells of the DB-ZR expressing b5 persisted in between the large vacuolated cells characteristic of a functional ZF and the large, spongy b5-positive cells of a diminishing FZ (Fig. 2D). Expression was greater in the outermost cells of the DB-ZR and decreased toward the FZ, but involved nearly all cells. The FZ continued to shrink, while the DB-ZR persisted and increased in relative width throughout the neonatal period (Fig. 2E and F). By 3 months of age, the DB-ZR exhibited uniform, intense expression of b5, similar to the ZR of the adult rhesus macaque (Fig. 2F and $\mathrm{H}$ ). A thin layer (1-2 cells thick) of b5-positive FZ cells (characterized based on the morphology previously described) persisted in juveniles (4-14 months; Fig. 2G). No FZ cells were observed in adrenal glands from adult animals (Fig. $2 \mathrm{H}$ ), and no b5 immunostaining was detected in the DZ, ZG, ZF, or medulla of any adrenal sample. The pattern of expression of $b 5$ expression as described above for each age was evident and consistent in all specimens examined of similar age.

\section{Localization of HSD3B2}

Expression of HSD3B2 was restricted to the DZ and the outermost region of the $\mathrm{TZ}$ during the perinatal period, but did not extend into the DB-ZR or FZ (Fig. 3A). As differentiation proceeded, expression of HSD3B2 was confined to the $\mathrm{ZG}$ and $\mathrm{ZF}$ of the neonatal and juvenile adrenal cortex, but remained consistently absent from the DB-ZR and FZ (Fig. 3B and C). In all specimens examined, HSD3B2 was expressed intensely in all cells of the DZ, and in sections from older animals, and nearly all ZG and ZF cells were positive. The intensity of expression was similar among cells of the outermost TZ and the ZF cells. No immunostaining was detected in cells of the medulla, DB-ZR, FZ, or ZR of any specimen. The pattern of HSD3B2 expression described above was consistent among all similarly aged specimens.

\section{Localization of CYP21A2}

Expression of CYP21A2 was localized throughout the DZ, $\mathrm{TZ}$, and DB-ZR of the adrenal cortex of perinatal adrenal glands (Fig. 3D), and immunostaining was intense and uniform throughout the DZ and outermost TZ. All cells of the TZ expressed CYP21A2. CYP21A2 expression in the DB-ZR was patchy, with the cells at the TZ/DB-ZR border exhibiting the greatest intensity and the number of positive cells. By contrast, CYP21A2 expression was essentially absent from the FZ, even faintly immunopositive cells were rare (Fig. 3D). This pattern of CYP21A2 expression persisted through the perinatal and neonatal stages with marked expression throughout the $\mathrm{ZG}, \mathrm{ZF}$, and $\mathrm{DB}-\mathrm{ZR}$, but a relative lack of CYP21A2 expression in the FZ (Fig. 3E and F). By contrast, the proportion of DB-ZR cells that were immunopositive for CYP21A2 greatly increased with age in neonates (Fig. 3E) to include all cells in this band, rather than those primarily at the TZ border, as in the perinatal adrenals. CYP21A2 expression was undetected in the remaining FZ cells (Fig. 3E). In the adrenal cortex of juvenile rhesus macaques (Fig. 3F), CYP21A2 was expressed in nearly all cells of the $Z G$ and $Z F$, with continued patchy expression throughout the established ZR. The FZ cells of the juvenile adrenal similarly lacked CYP21A2 expression and continued to decrease in cell numbers and general size compared with the neonatal adrenal. No cellular expression was observed in the medulla of any adrenal samples. This was a consistent pattern evident in all specimens examined of similar age.

\section{Localization of CYP17A1}

CYP17A1 was detected throughout the TZ and FZ of the perinatal adrenal cortex (Fig. 4A). Expression was sparse and faint in the large, vacuolated cells of the FZ, while nearly all cells of the outer TZ exhibited intense staining. Expression of CYP17A1 that was observed in the cells of the DB-ZR was intermediate in intensity compared with $\mathrm{FZ}$ and $\mathrm{TZ}$ staining (Fig. 4A). A similar pattern of CYP17A1 expression was observed in neonatal adrenal specimens (1-3 months old), with CYP17A1 localized throughout the large cells of the ZF and the compact cells of the DB-ZR (Fig. 4B). Expression of CYP17A1 was barely detectable in the vacuolated cells of the FZ during this period. After the establishment of a morphologically mature ZR (more than 3 months old), CYP17A1 expression was observed throughout the $Z F$ and $\mathrm{ZR}$, with expression in nearly all cells of the $\mathrm{ZF}$ and patchy expression throughout the ZR (Fig. 4C). ZF cells exhibited generally greater intensity of CYP17A1 expression than ZR cells. There was no detectable expression of CYP17A1 in the 
medulla, DZ, or ZG of samples studied. As for other enzymes examined, the pattern of expression was consistent in all specimens of similar age.

\section{Localization of CPR}

Expression of CPR was detected in all cells of all zones and throughout the adrenal cortex of all specimens regardless of age. Adrenocortical cells at the corticomedullary junction exhibited the greatest CPR expression in the majority of samples (Fig. 4D-F); otherwise, expression was uniform throughout the cortex. Cellular expression of CPR was undetectable in the medulla of any adrenal specimen.

\section{Discussion}

As recently described (Havelock et al. 2004), adrenarche occurs in humans as a result of maturation of the ZR, and although rhesus macaques experience similar cortical differentiation (Mapes et al. 1999), they are generally not thought to experience adrenarche (Arlt et al. 2002). Previously, we and others have demonstrated that $\mathrm{b} 5$ is an effective marker of $\mathrm{ZR}$ differentiation and, along with CYP17A1 expression, androgen synthetic capacity of rhesus and human adrenal tissues including the FZ (Sakai et al. 1993, Yanase et al. 1998, Narasaka et al. 2001, Mapes et al. 2002, Dharia et al. 2004). Neither the origins of the cells of the ZR, nor their relationship to the FZ, is well understood in non-human primate species. The characterization of $\mathrm{b} 5$ expression in the neonatal rhesus adrenal cortex presented here helps clarify both these issues. Based on morphology and a general lack of CYP21A2 expression in the FZ compared with the ZR, the cells of these two adrenal zones exhibit different steroidogenic phenotypes. The expression of CYP21A2 in the DB-ZR and its resemblance to the $\mathrm{ZR}$ therefore supports the view expressed by McNulty and colleagues based on morphology alone (McNulty et al. 1981) that the ZR develops from their so-called 'dense band'. ZR development and FZ regression are also clearly coincident events in the rhesus (Fig. 5) as evidenced by the delineation of both of these zones in the perinatal and neonatal adrenal gland. This supports the view that they have different origins and fates. We conclude that the rhesus macaque experiences the same developmental event defined as adrenarche in humans based on histological differentiation of the ZR (Havelock et al. 2004), but that it is concurrent with $\mathrm{FZ}$ regression and compressed into the first of 2-3 months of life, complicating recognition by analysis of peripheral androgen concentrations.

While the FZ and ZR of human and non-human primate (rhesus) adrenal glands have similar potential for androgen secretion, their temporal patterns of development and differentiation differ greatly. In humans, FZ expression of the steroidogenic enzymes involved in androgen synthesis persists from mid-gestation to term, coinciding with increases in secretion of DHEA and DS (Parker et al. 1982, Mesiano
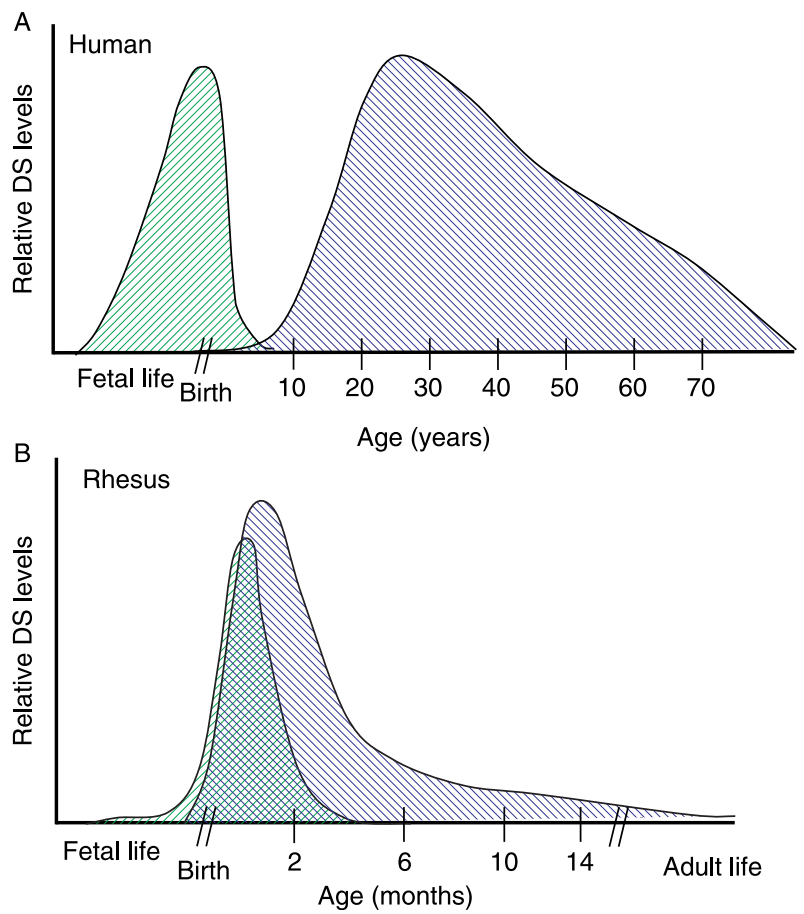

Figure 5 Representation of dehydroepiandrosterone (DS) profiles in humans and rhesus macaques with major adrenocortical events demarcated. Green, upward diagonal areas indicate the chronological span of the active FZ. Blue, downward diagonal areas indicate the chronological span of the active ZR. (A) Changing DS levels with age in humans, based on data from published reports (Abraham et al. 1973, Parker et al. 1978, 1982, de Peretti \& Forest 1978, Orentreich et al. 1992, Belanger et al. 1994, Lasley et al. 2002). (B) Changing DS levels with age in rhesus macaques, based on data from published reports (Cutler et al. 1978, Smail et al. 1982, Koritnik et al. 1983, Seron-Ferre et al. 1983, Walsh et al. 1984, Pepe et al. 1988, Conley et al. 2004). Note the overlap between the active FZ and the active ZR (cross-hatched) during early life in the rhesus.

et al. 1993, Narasaka et al. 2001). During the first year of life, there is a marked decline in circulating DHEA and DS levels associated with the involution of the human FZ (Benner 1940, de Peretti \& Forest 1976, 1978), and with decreased expression of CYP17A1, DHEA sulfotransferase, b5, and CPR throughout the adrenal cortex (Suzuki et al. 2000). By the fifth or sixth year of life, levels of DHEA and DS rise detectably (Rosenfield \& Eberlein 1969, Rosenfield et al. 1969), marking the onset of adrenarche (de Peretti \& Forest 1976, 1978, Parker et al. 1978). Thus, human ZR differentiation begins years after complete regression of the FZ (Suzuki et al. 2000), and is marked by increased CYP17A1 and $\mathrm{b} 5$ expression in the fifth year of life, as well as by a fully differentiated zone with reduced HSD3B2 expression by 8 years of age (Endoh et al. 1996, Gell et al. 1998, Suzuki et al. 2000). Consequently, the long temporal separation between FZ regression and differentiation of the ZR in humans makes the two events easily distinguished by changes in circulating DS after birth. 
In comparison to humans, DS concentrations in the rhesus fetus are generally lower during gestation, but increase immediately pre-partum (Seron-Ferre et al. 1983, Walsh et al. 1984). This pre-partum rise in fetal serum DS coincides with increasing adrenal expression of CYP17A1 and b5 during late fetal development (Mapes et al. 2002). Results of the current IHC studies show that the establishment of a morphologically mature $\mathrm{ZR}$ in the neonatal rhesus macaque resembles human adrenarche (Havelock et al. 2004), although its appearance coincides with regression of the FZ. The earliest studies investigating this phenomenon in the rhesus reported only that adrenal androgens declined in animals older than 2-4 months of age (Cutler et al. 1978, Smail et al. 1982), and not observing any preceding increase, concluded therefore that this species does not experience an adrenarche. However, our data demonstrate that rhesus ZR development begins in late gestation (Mapes et al. 2002) and as shown here is essentially completed in the third month of life. Whereas regression of the FZ and maturation of the $\mathrm{ZR}$ are temporally separated by years in humans, both events occur concurrently, compressed within the first two months of life in the rhesus macaque. In contrast to the onset of $\mathrm{ZR}$ differentiation, which is pre-pubertal in both rhesus and human, the peak in DS concentrations differs markedly, preceding puberty in rhesus, but post-dating puberty in humans by more than a decade. This does not indicate any fundamental difference exists between human and rhesus adrenal with respect to ZR development. In fact, it is entirely consistent with the physiological independence of ZR development from gonadal function, as evidenced in normal children and those with precocious puberty (Sklar et al. 1980, Palmert et al. 2001, Remer et al. 2005). Although the decline in DS (adrenopause) is readily detectable in the rhesus, adrenarche is certainly not. Since both the FZ and ZR have the capacity for DS synthesis and secretion (Conley et al. 2004), we propose that the loss of androgen secretion from the regressing FZ likely masks increased secretion by the developing ZR, making adrenarche in the rhesus macaque a cryptic event when based on circulating DS concentrations alone.

The concurrence of FZ regression with ZR differentiation during neonatal rhesus adrenocortical development described here has additional implications for the regulation of these processes. Despite observations suggesting human FZ regression occurred by massive cellular collapse involving necrosis (as reviewed (Lanman 1953)), it is more likely that involution of the FZ is gradual (Scammon 1926, Benner 1940, Sucheston \& Cannon 1968). In agreement with the latter reports, McNulty et al. (1981) noted a gradual reduction in FZ width without necrosis or signs of involution in the neonatal rhesus adrenal cortex. Using the markers b5 and CYP21A2, in addition to morphology, our data confirm that the rhesus FZ undergoes a progressive, if more rapid, regression post-natally than that seen in humans. However, what the concurrence of FZ regression with ZR development suggests is that different growth factors or regulatory processes mediate these two events. Although able to stimulate CYP17A1 expression in cultured fetal adrenal cells (Di Blasio et al. 1987), proopiomelanocortin (POMC) likely plays more of a permissive (as reviewed (Parker \& Odell 1980, Auchus \& Rainey 2004)), rather than an inductive role, in adrenal development as POMC and cortisol levels remain steady during this developmental window (Apter et al. 1979, Parker \& Odell 1980). Epidermal growth factor (EGF), which promotes steroid synthesis in cultured human fetal adrenal cells, may play a role in maturation of the FZ or developing ZR (Jaffe et al. 1981). EGF increases expression of HSD3B2 in the TZ and DZ and stimulates fetal adrenal gland growth (Coulter et al. 1996c). IGFs may also regulate adrenal growth via IGF receptors and binding proteins that are localized throughout the fetal adrenal cortex in rhesus (Coulter et al. 1996a). IGF1 was correlated positively with increased androstenedione levels in Hispanic and African-American women who experienced premature adrenarche (l'Allemand et al. 2002). Additionally, IGF2 expression in human fetal adrenal cells is induced by POMC (Voutilainen \& Miller 1987), further evidence linking IGFs with POMC and adrenal growth. The rhesus may prove useful in studying regulatory factors, and their interactions, as putative determinants of FZ regression and ZR induction in shortterm studies because of the much shortened period of adrenocortical differentiation.

The expression of b5 throughout the developing and mature ZR further highlights the importance of b5 in the modulation of androgen synthesis (Onoda \& Hall 1982, Shinzawa et al. 1985, Mapes et al. 1999). The enzymatic activities of CYP17A1 are differentially regulated, as evidenced in children undergoing adrenarche and patients with isolated 17,20-lyase deficiency (Kaufman et al. 1983, Geller et al. 1997, Van Den Akker et al. 2002, Sherbet et al. 2003). The accessory protein b5 (Onoda \& Hall 1982, Katagiri et al. 1995, Lee-Robichaud et al. 1995), serine phosphorylation of CYP17A1 (Zhang et al. 1995), and/or increased molar ratios of CPR (Yanagibashi \& Hall 1986) stimulate 17,20 -lyase activity over $17 \alpha$-hydroxylase activity, increasing the capacity for DHEA production (Pandey \& Miller 2005). While b5 facilitates electron transfer with some microsomal P450s (Kurian et al. 2004), evidence suggests this is not the mechanism of action for stimulation of 17,20-lyase activity (Auchus et al. 1998). An allosteric action of b5, thought to promote complex formation between CYP17A1 and CPR, has been suggested (Auchus et al. 1998, Pandey \& Miller 2005). Co-localization of CYP17A1 and b5 has been demonstrated previously in androgenic tissues of human and non-human primates (Mapes et al. 1999, 2002, Suzuki et al. 2000, Dharia et al. 2004, Pattison et al. 2007) and in human adrenal disease (Yanase et al. 1998). Increased expression of b5 may account for increased adrenal androgen production with endocrinological disorders (Sakai et al. 1993), in addition to stimulation of synthesis during endocrinological transitions. However, the role of b5 in adrenarche has not been as carefully evaluated in human tissues, and further studies are 
necessary to determine its contribution to changes in adrenal androgen secretion during development.

Classically, adrenarche has been defined based on circulating DS concentrations, one of the few easily measured markers of this event. Recent longitudinal studies conducted from early childhood (Remer \& Manz 1999, Palmert et al. 2001, Remer et al. 2005), adding to earlier reports (Sizonenko et al. 1976, Parker et al. 1978, Ilondo et al. 1982, Kelnar \& Brook 1983), indicate that adrenarche is associated with a gradual, rather than abrupt, rise in adrenal androgen production, but this is not the pattern seen in the rhesus macaque. As noted earlier, DS levels are high in the rhesus soon after birth, but decline rapidly between 2 and 3 months of age then more gradually throughout the rest of life (Koritnik et al. 1983, Seron-Ferre et al. 1983, 1986, Kemnitz et al. 2000). Although our data suggest that the concurrence of FZ regression with ZR differentiation likely make it difficult to distinguish these events from each other based on circulating DS, there may be other equally important confounding factors. For instance, it has been suggested that efficient metabolism of DHEA, specifically 16 $\alpha$-hydroxylation, in early childhood and adolescence may mask a significant portion of the adrenal androgens secreted during early human development, most often estimated from DHEA and DS levels only (Remer et al. 2005). In addition, changes in glucuronidation (Guillemette et al. 1996) and even sulfotransferase itself, which we have shown is expressed in the rhesus adrenal (Parker et al. 2000), along with other routes of androgen metabolism (Remer et al. 2005), may alter apparent adrenal androgen output. All of the above make peripheral hormone levels potentially poor indices of adrenal development in non-human primates. Adrenarche can be defined in histochemical and even biochemical terms if tissues are available for such analyses and, though not clinically useful, are relevant nonetheless because circulating hormone concentrations may not accurately reflect the underlying biology, especially in non-human primate models.

We believe that the late gestational, perinatal, and neonatal rhesus macaque is a suitable model for study of adrenarche, and potentially also for hyperandrogenic syndromes such as polycystic ovarian disease (Abbott et al. 2008). The processes and factors involved in primate adrenal maturation are complex, as evidenced by the gender and gonadal differences in ZR function in marmosets (Pattison et al. 2007). Studies examining the capacity for androgen production during this dynamic period, as well as investigation into the regulation of $\mathrm{ZR}$ development, are necessary to properly characterize the morphological adrenarche exhibited by the rhesus.

\section{Declaration of interest}

There is no conflict of interest that could be perceived as prejudicing the impartiality of the research reported.

\section{Funding}

This research did not receive any specific grant from any funding agency in the public, commercial or not-for-profit sector.

\section{Acknowledgements}

The authors would like to thank Dr Alice Tarantal and the animal technical staff of the California National Primate Research Center for collection of adrenal samples, and Drs Justin Vidal and Patience Browne for training and assistance with IHC procedures.

\section{References}

Abbott DH, Zhou R, Bird IM, Dumesic DA \& Conley AJ 2008 Fetal programming of adrenal androgen excess: lessons from a nonhuman primate model of polycystic ovary syndrome. Endocrine Development 13 145-158.

Abraham GE, Buster JE, Kyle FW, Corrales PC \& Teller RC 1973 Radioimmunoassay of plasma pregnenolone, 17-hydroxypregnenolone and dehydroepiandrosterone under various physiological conditions. Journal of Clinical Endocrinology and Metabolism 37 140-144.

Van Den Akker EL, Koper JW, Boehmer AL, Themmen AP, Verhoef-Post M, Timmerman MA, Otten BJ, Drop SL \& de Jong FH 2002 Differential inhibition of 17alpha-hydroxylase and 17,20-lyase activities by three novel missense CYP17 mutations identified in patients with P450c17 deficiency. Journal of Clinical Endocrinology and Metabolism 87 5714-5721.

l'Allemand D, Schmidt S, Rousson V, Brabant G, Gasser T \& Gruters A 2002 Associations between body mass, leptin, IGF-I and circulating adrenal androgens in children with obesity and premature adrenarche. European Journal of Endocrinology 146 537-543.

Apter D, Pakarinen A, Hammond GL \& Vihko R 1979 Adrenocortical function in puberty, serum ACTH, cortisol and dehydroepiandrosterone in girls and boys. Acta Paediatrica Scandinavica 68 599-604.

Arlt W, Martens JW, Song M, Wang JT, Auchus RJ \& Miller WL 2002 Molecular evolution of adrenarche: structural and functional analysis of p450c17 from four primate species. Endocrinology 143 4665-4672.

Auchus RJ \& Rainey WE 2004 Adrenarche - physiology, biochemistry and human disease. Clinical Endocrinology 60 288-296.

Auchus RJ, Lee TC \& Miller WL 1998 Cytochrome b5 augments the 17,20lyase activity of human P450c17 without direct electron transfer. Journal of Biological Chemistry 273 3158-3165.

Belanger A, Candas B, Dupont A, Cusan L, Diamond P, Gomez JL \& Labrie F 1994 Changes in serum concentrations of conjugated and unconjugated steroids in 40- to 80-year-old men. Journal of Clinical Endocrinology and Metabolism 79 1086-1090.

Benner SA 1940 Studies on the involution of the fetal cortex of the adrenal glands. American Journal of Pathology 16 787-798.

Di Blasio AM, Voutilainen R, Jaffe RB \& Miller WL 1987 Hormonal regulation of messenger ribonucleic acids for P450scc (cholesterol sidechain cleavage enzyme) and P450c17 (17 alpha- hydroxylase/17,20-lyase) in cultured human fetal adrenal cells. Journal of Clinical Endocrinology and Metabolism 65 170-175.

Browne P, Place NJ, Vidal JD, Moore IT, Cunha GR, Glickman SE \& Conley AJ 2006 Endocrine differentiation of fetal ovaries and testes of the spotted hyena (Crocuta crocuta): timing of androgen-independent versus androgendriven genital development. Reproduction 132 649-659.

Conley AJ \& Bird IM 1997 The role of cytochrome P450 17 alphahydroxylase and 3 beta-hydroxysteroid dehydrogenase in the integration of gonadal and adrenal steroidogenesis via the delta 5 and delta 4 pathways of steroidogenesis in mammals. Biology of Reproduction 56 789-799.

Conley AJ, Corbin CJ, Hinshelwood MM, Liu Z, Simpson ER, Ford JJ \& Harada N 1996 Functional aromatase expression in porcine adrenal gland and testis. Biology of Reproduction 54 497-505. 
Conley AJ, Pattison JC \& Bird IM 2004 Variations in adrenal androgen production among (nonhuman) primates. Seminars in Reproductive Medicine 22 311-326.

Coulter CL \& Jaffe RB 1998 Functional maturation of the primate fetal adrenal in vivo: 3 . Specific zonal localization and developmental regulation of CYP21A2 (P450c21) and CYP11B1/CYP11B2 (P450c11/aldosterone synthase) lead to integrated concept of zonal and temporal steroid biosynthesis. Endocrinology 139 5144-5150.

Coulter CL, Goldsmith PC, Mesiano S, Voytek CC, Martin MC, Han VK \& Jaffe RB 1996 a Functional maturation of the primate fetal adrenal in vivo: I. Role of insulin-like growth factors (IGFs), IGF-I receptor, and IGF binding proteins in growth regulation. Endocrinology 137 4487-4498.

Coulter CL, Goldsmith PC, Mesiano S, Voytek CC, Martin MC, Mason JI \& Jaffe RB $1996 b$ Functional maturation of the primate fetal adrenal in vivo. II. Ontogeny of corticosteroid synthesis is dependent upon specific zonal expression of 3 beta-hydroxysteroid dehydrogenase/isomerase. Endocrinology 137 4953-4959.

Coulter CL, Read LC, Carr BR, Tarantal AF, Barry S \& Styne DM 1996c A role for epidermal growth factor in the morphological and functional maturation of the adrenal gland in the fetal rhesus monkey in vivo. Journal of Clinical Endocrinology and Metabolism 81 1254-1260.

Cutler GJ, Glenn M, Bush M, Hodgen GD, Graham CE \& Loriaux DL 1978 Adrenarche: a survey of rodents, domestic animals, and primates. Endocrinology 103 2112-2118.

Dharia S, Slane A, Jian M, Conner M, Conley AJ \& Parker CR Jr 2004 Colocalization of $\mathrm{P} 450 \mathrm{c} 17$ and cytochrome b5 in androgen-synthesizing tissues of the human. Biology of Reproduction 71 83-88.

Dharia S, Slane A, Jian M, Conner M, Conley AJ, Brissie RM \& Parker CR Jr 2005 Effects of aging on cytochrome b5 expression in the human adrenal gland. Journal of Clinical Endocrinology and Metabolism 90 4357-4361.

Doody KM, Carr BR, Rainey WE, Byrd W, Murry BA, Strickler RC, Thomas JL \& Mason JI 1990 3ß-Hydroxysteroid dehydrogenase/isomerase in the fetal zone and neocortex of the human fetal adrenal gland. Endocrinology 126 2487-2492.

Endoh A, Kristiansen SB, Casson PR, Buster JE \& Hornsby PJ 1996 The zona reticularis is the site of biosynthesis of dehydroepiandrosterone and dehydroepiandrosterone sulfate in the adult human adrenal cortex resulting from its low expression of 3 beta- hydroxysteroid dehydrogenase. Journal of Clinical Endocrinology and Metabolism 81 3558-3565.

Gell JS, Carr BR, Sasano H, Atkins B, Margraf L, Mason JI \& Rainey WE 1998 Adrenarche results from development of a 3beta-hydroxysteroid dehydrogenase-deficient adrenal reticularis. Journal of Clinical Endocrinology and Metabolism 83 3695-3701.

Geller DH, Auchus RJ, Mendonca BB \& Miller WL 1997 The genetic and functional basis of isolated 17,20-lyase deficiency. Nature Genetics 17 201-205.

Guillemette C, Hum DW \& Belanger A 1996 Levels of plasma C19 steroids and 5 alpha-reduced C19 steroid glucuronides in primates, rodents, and domestic animals. American Journal of Physiology 271 E348-E353.

Havelock JC, Auchus RJ \& Rainey WE 2004 The rise in adrenal androgen biosynthesis: adrenarche. Seminars in Reproductive Medicine 22 337-347.

Ilondo MM, Vanderschueren-Lodeweyckx M, Vlietinck R, Pizarro M, Malvaux P, Eggermont E \& Eeckels R 1982 Plasma androgens in children and adolescents. Part I: control subjects. Hormone Research 16 61-77.

Jaffe RB, Seron-Ferre M, Crickard K, Koritnik D, Mitchell BF \& Huhtaniemi IT 1981 Regulation and function of the primate fetal adrenal gland and gonad. Recent Progress in Hormone Research 37 41-103.

Jaffe RB, Mesiano S, Smith R, Coulter CL, Spencer SJ \& Chakravorty A 1998 The regulation and role of fetal adrenal development in human pregnancy. Endocrine Research 24 919-926.

Katagiri M, Kagawa N \& Waterman MR 1995 The role of cytochrome b5 in the biosynthesis of androgens by human P450c17. Archives of Biochemistry and Biophysics 317 343-347.

Kaufman FR, Costin G, Goebelsmann U, Stanczyk FZ \& Zachmann M 1983 Male pseudohermaphroditism due to 17,20-desmolase deficiency. Journal of Clinical Endocrinology and Metabolism 57 32-36.
Kelnar CJ \& Brook CG 1983 A mixed longitudinal study of adrenal steroid excretion in childhood and the mechanism of adrenarche. Clinical Endocrinology 19 117-129.

Kemnitz JW, Roecker EB, Haffa AL, Pinheiro J, Kurzman I, Ramsey JJ \& MacEwen EG 2000 Serum dehydroepiandrosterone sulfate concentrations across the life span of laboratory-housed rhesus monkeys. Journal of Medical Primatology 29 330-337.

Koritnik DR, Laherty RF, Rotten D \& Jaffe RB 1983 A radioimmunoassay for dehydroepiandrosterone sulfate in the circulation of rhesus monkeys. Steroids 42 653-667.

Kurian JR, Bajad SU, Miller JL, Chin NA \& Trepanier LA 2004 NADH cytochrome b5 reductase and cytochrome b5 catalyze the microsomal reduction of xenobiotic hydroxylamines and amidoximes in humans. Journal of Pharmacology and Experimental Therapeutics 311 1171-1178.

Lanman JT 1953 The fetal zone of the adrenal gland - its developmental course, comparative anatomy, and possible physiologic functions. Medicine 32 389-430.

Lasley BL, Santoro N, Randolf JF, Gold EB, Crawford S, Weiss G, McConnell DS \& Sowers MF 2002 The relationship of circulating dehydroepiandrosterone, testosterone, and estradiol to stages of the menopausal transition and ethnicity. Journal of Clinical Endocrinology and Metabolism 87 3760-3767.

Lee-Robichaud P, Wright JN, Akhtar ME \& Akhtar M 1995 Modulation of the activity of human 17 alpha-hydroxylase-17,20-lyase CYP17 by cytochrome b5: endocrinological and mechanistic implications. Biochemical Journal 308 901-908.

Mapes S, Corbin CJ, Tarantal A \& Conley A 1999 The primate adrenal zona reticularis is defined by expression of cytochrome b5, 17alpha-hydroxylase/17,20-lyase cytochrome P450 (P450c17) and NADPH-cytochrome $\mathrm{P} 450$ reductase (reductase) but not 3beta-hydroxysteroid dehydrogenase/ delta5-4 isomerase (3beta-HSD). Journal of Clinical Endocrinology and Metabolism 84 3382-3385.

Mapes S, Tarantal AF, Parker CR, Moran FM, Bahr JM, Pyter L \& Conley AJ 2002 Adrenocortical cytochrome b5 expression during fetal development of the rhesus macaque. Endocrinology 143 1451-1458.

McNulty WP, Novy MJ \& Walsh SW 1981 Fetal and postnatal development of the adrenal glands in Macaca mulatta. Biology of Reproduction 25 1079-1089.

Mesiano S, Coulter CL \& Jaffe RB 1993 Localization of cytochrome P450 cholesterol side-chain cleavage, cytochrome P450 17 alpha-hydroxylase/17, 20-lyase, and 3 beta- hydroxysteroid dehydrogenase isomerase steroidogenic enzymes in human and rhesus monkey fetal adrenal glands: reappraisal of functional zonation. Journal of Clinical Endocrinology and Metabolism 77 1184-1189.

Narasaka T, Suzuki T, Moriya T \& Sasano H 2001 Temporal and spatial distribution of corticosteroidogenic enzymes immunoreactivity in developing human adrenal. Molecular and Cellular Endocrinology 174 111-120.

Nelson HP, Kuhn RW, Deyman ME \& Jaffe RB 1990 Human fetal adrenal definitive and fetal zone metabolism of pregnenolone and corticosterone: alternate biosynthetic pathways and absence of detectable aldosterone synthesis. Journal of Clinical Endocrinology and Metabolism 70 693-698.

Onoda M \& Hall PF 1982 Cytochrome b5 stimulates purified testicular microsomal cytochrome P- 450 (C21 side-chain cleavage). Biochemical and Biophysical Research Communications 108 454-460.

Orentreich N, Brind JL, Vogelman JH, Andres R \& Baldwin H 1992 Long-term longitudinal measurements of plasma dehydroepiandrosterone sulfate in normal men. Journal of Clinical Endocrinology and Metabolism 75 1002-1004.

Palmert MR, Hayden DL, Mansfield MJ, Crigler JF Jr, Crowley WF Jr, Chandler DW \& Boepple PA 2001 The longitudinal study of adrenal maturation during gonadal suppression: evidence that adrenarche is a gradual process. Journal of Clinical Endocrinology and Metabolism 86 4536-4542.

Pandey AV \& Miller WL 2005 Regulation of 17,20 lyase activity by cytochrome b5 and by serine phosphorylation of P450c17. Journal of Biological Chemistry 280 13265-13271.

Parker LN \& Odell WD 1980 Control of adrenal androgen secretion. Endocrine Reviews 1 392-410. 
Parker LN, Sack J, Fisher DA \& Odell WD 1978 The adrenarche: prolactin, gonadotropins, adrenal androgens, and cortisol. Journal of Clinical Endocrinology and Metabolism 46 396-401.

Parker CR Jr, Leveno K, Carr BR, Hauth J \& MacDonald PC 1982 Umbilical cord plasma levels of dehydroepiandrosterone sulfate during human gestation. Journal of Clinical Endocrinology and Metabolism 54 1216-1220.

Parker CJ, Jian M \& Conley AJ 2000 The localization of DHEA sulfotransferase in steroidogenic and steroid metabolizing tissues of the adult rhesus macaque monkey. Endocrine Research 26 517-522.

Pattison JC, Saltzman W, Abbott DH, Hogan BK, Nguyen AD, Husen B, Einspanier A, Conley AJ \& Bird IM 2007 Gender and gonadal status differences in zona reticularis expression in marmoset monkey adrenals: cytochrome b5 localization with respect to cytochrome P450 17,20-lyase activity. Molecular and Cellular Endocrinology 265-266 93-101.

Pepe GJ, Waddell BJ \& Albrecht ED 1988 The effects of adrenocorticotropin and prolactin on adrenal dehydroepiandrosterone secretion in the baboon fetus. Endocrinology 122 646-650.

de Peretti E \& Forest MG 1976 Unconjugated dehydroepiandrosterone plasma levels in normal subjects from birth to adolescence in human: the use of a sensitive radioimmunoassay. Journal of Clinical Endocrinology and Metabolism 43 982-991.

de Peretti E \& Forest MG 1978 Pattern of plasma dehydroepiandrosterone sulfate levels in humans from birth to adulthood: evidence for testicular production. Journal of Clinical Endocrinology and Metabolism 47 572-577.

Remer T \& Manz F 1999 Role of nutritional status in the regulation of adrenarche. Journal of Clinical Endocrinology and Metabolism 84 3936-3944.

Remer T, Boye KR, Hartmann MF \& Wudy SA 2005 Urinary markers of adrenarche: reference values in healthy subjects, aged 3-18 years. Journal of Clinical Endocrinology and Metabolism 90 2015-2021.

Rosenfield RL \& Eberlein WR 1969 Plasma 17-ketosteroid levels during adolescence. Journal of Pediatrics 74 932-936.

Rosenfield RL, Bongiovanni AM, Eberlein WR \& Wright FH 1969 Plasma testosterone and dehydroepiandrosterone sulfate during puberty. Journal of Pediatrics 74 830-831.

Sakai Y, Yanase T, Takayanagi R, Nakao R, Nishi Y, Haji M \& Nawata H 1993 High expression of cytochrome b5 in adrenocortical adenomas from patients with Cushing's syndrome associated with high secretion of adrenal androgens. Journal of Clinical Endocrinology and Metabolism 76 1286-1290.

Scammon RE 1926 The prenatal growth and natal involution of the human suprarenal gland. Proceedings of the Society for Experimental Biology and Medicine 23 809-811.

Seron-Ferre M, Lawrence CC, Siiteri PK \& Jaffe RB 1978 Steroid production by definitive and fetal zones of the human fetal adrenal gland. Journal of Clinical Endocrinology and Metabolism 47 603-609.

Seron-Ferre M, Taylor NF, Rotten D, Koritnik DR \& Jaffe RB 1983 Changes in fetal rhesus monkey plasma dehydroepiandrosterone sulfate: relationship to gestational age, adrenal weight and preterm delivery. Journal of Clinical Endocrinology and Metabolism 57 1173-1178.

Seron-Ferre M, Hess DL, Lindholm U \& Jaffe RB 1986 Persistence of fetal zone function in the infant rhesus monkey adrenal gland. Journal of Clinical Endocrinology and Metabolism 62 460-465.
Sherbet DP, Tiosano D, Kwist KM, Hochberg Z \& Auchus RJ 2003 CYP17 mutation E305G causes isolated 17,20-lyase deficiency by selectively altering substrate binding. Journal of Biological Chemistry 278 48563-48569.

Shinzawa K, Kominami S \& Takemori S 1985 Studies on cytochrome P-450 (P-450 17 alpha,lyase) from guinea pig adrenal microsomes. Dual function of a single enzyme and effect of cytochrome b5. Biochimica et Biophysica Acta 833 151-160.

Sizonenko PC, Paunier L \& Carmignac D 1976 Hormonal changes during puberty. IV. Longitudinal study of adrenal androgen secretions. Hormone Research 7 288-302.

Sklar CA, Kaplan SL \& Grumbach MM 1980 Evidence for dissociation between adrenarche and gonadarche: studies in patients with idiopathic precocious puberty, gonadal dysgenesis, isolated gonadotropin deficiency, and constitutionally delayed growth and adolescence. Journal of Clinical Endocrinology and Metabolism 51 548-556.

Smail PJ, Faiman C, Hobson WC, Fuller GB \& Winter JS 1982 Further studies on adrenarche in nonhuman primates. Endocrinology 111 844-848.

Sucheston ME \& Cannon MS 1968 Development of zonular patterns in the human adrenal gland. Journal of Morphology 126 477-491.

Suzuki T, Sasano H, Takeyama J, Kaneko C, Freije WA, Carr BR \& Rainey WE 2000 Developmental changes in steroidogenic enzymes in human postnatal adrenal cortex: immunohistochemical studies. Clinical Endocrinology 53 739-747.

Voutilainen R \& Miller WL 1987 Coordinate tropic hormone regulation of mRNAs for insulin-like growth factor II and the cholesterol side-chaincleavage enzyme, P450scc [corrected], in human steroidogenic tissues. PNAS 84 1590-1594.

Walsh SW, Stanczyk FZ \& Novy MJ 1984 Daily hormonal changes in the maternal, fetal, and amniotic fluid compartments before parturition in a primate species. Journal of Clinical Endocrinology and Metabolism 58 629-639.

Winter JS 1992 Foetal and neonatal adrenocortical development. In The Adrenal Gland, pp 87-104. Ed. VH James. New York: Raven Press Ltd.

Yanagibashi K \& Hall PF 1986 Role of electron transport in the regulation of the lyase activity of $\mathrm{C} 21$ side-chain cleavage P-450 from porcine adrenal and testicular microsomes. Journal of Biological Chemistry 261 8429-8433.

Yanase T, Sasano H, Yubisui T, Sakai Y, Takayanagi R \& Nawata H 1998 Immunohistochemical study of cytochrome b5 in human adrenal gland and in adrenocortical adenomas from patients with Cushing's syndrome. Endocrine Journal 45 89-95.

Zhang LH, Rodriguez H, Ohno S \& Miller WL 1995 Serine phosphorylation of human P450c17 increases 17,20-lyase activity: implications for adrenarche and the polycystic ovary syndrome. PNAS 92 10619-10623.

\section{Received in final form 1 September 2008 Accepted 4 September 2008 Made available online as an Accepted Preprint 11 September 2008}

